\title{
Increased acquired protease inhibitor drug resistance mutations in minor HIV-1 quasispecies from infected patients suspected of failing on national second-line therapy in South Africa
}

\author{
Adetayo Emmanuel Obasa ${ }^{1,2^{*}}$ (D) Anoop T. Ambikan², Soham Gupta ${ }^{2}$, Ujjwal Neogi ${ }^{2}$ and Graeme Brendon Jacobs ${ }^{1 \wedge}$
}

\begin{abstract}
Background: HIV-1C has been shown to have a greater risk of virological failure and reduced susceptibility towards boosted protease inhibitors (bPIs), a component of second-line combination antiretroviral therapy (CART) in South Africa. This study entailed an evaluation of HIV-1 drug resistance-associated mutations (RAMs) among minor viral populations through high-throughput sequencing genotypic resistance testing (HTS-GRT) in patients on the South African national second-line CART regimen receiving bPIs.
\end{abstract}

Methods: During 2017 and 2018, 67 patient samples were sequenced using high-throughput sequencing (HTS), of which 56 samples were included in the final analysis because the patient's treatment regimen was available at the time of sampling. All patients were receiving bPIs as part of their CART. Viral RNA was extracted, and complete pol genes were amplified and sequenced using Illumina HiSeq2500, followed by bioinformatics analysis to quantify the RAMs according to the Stanford HIV Drug Resistance Database.

Results: Statistically significantly higher PI RAMs were observed in minor viral quasispecies (25\%; 14/56) compared to non-nucleoside reverse transcriptase inhibitors $(9 \% ; 5 / 56 ; p=0.042)$ and integrase inhibitor RAM $(4 \% ; 2 / 56 ; p=$ 0.002). The majority of the drug resistance mutations in the minor viral quasispecies were observed in the V82A mutation $(n=13)$ in protease and $\operatorname{K65R}(n=5), \operatorname{K103N}(n=7)$ and M184V $(n=5)$ in reverse transcriptase.

Conclusions: HTS-GRT improved the identification of PI and reverse transcriptase inhibitor (RTI) RAMs in second-line cART patients from South Africa compared to the conventional GRT with $\geq 20 \%$ used in Sanger-based sequencing. Several RTI RAMs, such as K65R, M184V or K103N and PI RAM V82A, were identified in < 20\% of the population. Deep sequencing could be of greater value in detecting acquired resistance mutations early.

Keywords: High-throughput sequencing (HTS), Boosted protease inhibitors (bPIs), Non-nucleoside reverse transcriptase inhibitors (NNRTIs), Nucleoside reverse transcriptase inhibitors (NRTIs)

\footnotetext{
* Correspondence: obasa@sun.ac.za

Graeme Brendon Jacobs is deceased.

'Department of Pathology, Division of Medical Virology, Faculty of Medicine and Health Sciences, Stellenbosch University, Tygerberg, Cape Town 7505,

South Africa

${ }^{2}$ Department of Laboratory Medicine, Division of Clinical Microbiology,

Karolinska Institute, Stockholm, Sweden
}

C C The Author(s). 2021 Open Access This article is licensed under a Creative Commons Attribution 4.0 International License, which permits use, sharing, adaptation, distribution and reproduction in any medium or format, as long as you give appropriate credit to the original author(s) and the source, provide a link to the Creative Commons licence, and indicate if changes were made. The images or other third party material in this article are included in the article's Creative Commons licence, unless indicated otherwise in a credit line to the material. If material is not included in the article's Creative Commons licence and your intended use is not permitted by statutory regulation or exceeds the permitted use, you will need to obtain permission directly from the copyright holder. To view a copy of this licence, visit http://creativecommons.org/licenses/by/4.0/ The Creative Commons Public Domain Dedication waiver (http://creativecommons.org/publicdomain/zero/1.0/) applies to the data made available in this article, unless otherwise stated in a credit line to the data. 


\section{Background}

High-throughput sequencing (HTS) has unique advantages and significantly improves sensitivity in quantifying the minority HIV drug-resistant variants within HIV quasispecies [1]. Increased identification of pre-treatment minority drug resistance mutations (DRMs) compared to Sanger-based sequencing genotypic resistance testing (GRT) was reported from both resource-rich and resource-limited settings [2, 3]. The role of minority drug-resistant variants and their clinical consequences in the failure of combination antiretroviral therapy (cART) is debatable [4-18]. The presence of the minor variants remains unclear but clinical consequences cannot be ignored.

Studies have shown that even in adherent patients, those with pre-existing Y181C mutants have a triple higher risk of virological failure on an efavirenz-based cART regimen [19]. Several studies have shown that minority pre-treatment drug resistance was associated with reduced treatment efficacy for first-generation nonnucleoside reverse transcriptase inhibitors (NNRTIs), but not for rilpivirine and integrase inhibitors (INIs) [3, $17,20]$. In contrast, other studies have indicated that in a population with a relatively low prevalence of DRM, the use of deep sequencing to detect minority HIV-1 DRM has limited clinical benefit [21]. However, a study conducted by Inzaule et al., reported that incorporating the minor DRMs might improve the predictive value of GRT, but that very low thresholds of minority mutations can compromise the test specificity [22]. Data on acquired minority mutations on treatment-failure patients are limited.

In sub-Saharan Africa, South Africa has 23.6\% pretreatment drug resistance to efavirenz or NVP, followed by Namibia with $13.8 \%$, while Zimbabwe has $10.9 \%$ resistance to NVP [8]. HIV-1 subtype C (HIV-1C) is the major HIV-1 subtype in South Africa, responsible for more than $90 \%$ of infections. The recommended second-line cART consists of the nucleoside reverse transcriptase inhibitors (NRTIs) zidovudine or tenofovir and lamivudine and a ritonavir-boosted $(/ \mathrm{r})$ protease inhibitor $(\mathrm{PI})$, usually lopinavir $(\mathrm{LPV} / \mathrm{r})[23,24]$. Earlier studies from South Africa and Sweden reported that despite good adherence, there is an increased risk of virological failure in patients with HIV-1C on bPI-based regimens [20, 25]. Ex vivo and in vitro experiments also indicated large variations in susceptibility of $\mathrm{HIV}-1 \mathrm{C}$ viruses in the absence of PI resistance-associated mutations (RAMs) [26].

Studies have reported that the rates of virological failure on second-line cART are high in resource-limited settings, including South Africa, and are associated with the duration of exposure to previous drug regimens and poor adherence [27], mostly without any protease RAM [28]. In South Africa, with more than 4.5 million HIVinfected individuals accessing cART, approximately 145, $000(\sim 4 \%)$ are accessing second-line cART [29]. However, the drug resistance pattern in patients failing on bPIs is limited and often described by GRT through Sanger sequencing [30]. An earlier study with only seven patients indicated the presence of PI RAMs in bPIfailure patients, which was missed by bulk Sanger sequencing [31]. In clinical settings, Sanger bulk sequencing is the most common and widely used for HIV drug resistance testing. The limitation of the Sanger bulk sequencing method is that it can only detect variants with prevalence $>20 \%$ which is well known [32-34]. Studies have described the presence of minority HIV-1 drug resistance mutations in treatment-naive patients which could potentially impact treatment outcome [4, 13, 16, 19, 35]. Next-Generation Sequencing (NGS) method have the unique advantage of detecting of minority variants with a threshold as low as 1\%; although, this method can also generate errors, so when reporting lowfrequency, caution should be exercised [36, 37]. Therefore, the primary aim of the present study was to determine the level and pattern of HIV-1 drug resistance in minor $(<20 \%)$ and major viral populations in patients receiving bPIs.

\section{Methods}

\section{Ethics statement}

The study was approved by the Faculty of Medicine and Health Sciences, Health Research Ethics Committee (HREC) Stellenbosch University, South Africa (N15/08/ 071). The investigations also complies with the South Africa National Health Act No 612003 and abides by the ethical norms and principles for research as established by the Declaration of Helsinki, the South African Medical Research Council Guidelines as well as the Department of Health Guidelines. A waiver of written informed consent was awarded to conduct sequence analyses on these samples by the Health Research Ethics Committee of Stellenbosch University, South Africa.

\section{Viral load}

For HIV-1 viral load testing, we used the Abbott m2000sp and the Abbott m2000rt analyzers (Abbott Laboratories, Abbott Park, IL, USA). Viral RNA was isolated from patient samples according to the manufacturer's instructions using the Abbott RealTime HIV-1 Amplification Reagent Kit.

\section{Study design}

Convenient plasma samples were obtained from patients receiving bPIs as part of their treatment regimen (as referred by the clinician) with viral load $>900$ copies $/ \mathrm{mL}$ at the time of sampling from the diagnostic section at the Division of Medical Virology, Stellenbosch University, and the South African National Health Laboratory 
Services (NHLS), and were collected between March 2017 and February 2018 [20, 38]. We excluded patient samples with no previous cART regimen history and patients receiving first-line cART treatment regimens. Patients had their samples submitted for HIV-1 GRT to the NHLS. The NHLS provides routine genotypic antiretroviral drug resistance testing for clinics in the Western Cape, Gauteng and Eastern Cape provinces.

\section{PCR amplification and HTS}

Reverse transcriptase PCR (RT-PCR), which consists of cDNA synthesis followed by first-round PCR, was performed using the SuperScript ${ }^{\text {ti }}$ III One-Step RT-PCR System with Platinum $^{\text {m }}$ Taq DNA Polymerase (Invitrogen/Life Technology, Cat. No. 12574026) using the primers 1810F (5'-GCTACACTAGAAGAAATGATGA CAGCATG-3') and 5220R (5'-CCCTAGTGGGATGT GTACTTCTGA-3'). The second-round nested PCR was performed with 2001F (5'-TGCAGGGCCCCTAGGA AAAAGGGCTGTT-3') and 5087R (5' - ATCCTGTCTA CYTGCCACACAAYC-3') primers using the KAPA HiFi HotStart ReadyMix PCR kit. The amplified products were purified using the QIAamp gel extraction kit (Qiagen, Germany). For HTS, the purified amplicons were fragmented, and the library was prepared using NEBNext $^{\circ}$ Ultra $^{\text {Tx }}$ DNA Library Prep Kit for Illumina ${ }^{\circ}$ (New England Biolab, USA) with multiplexed NEB next adaptors. The samples were then pooled together with other unrelated non-viral indexed libraries. Paired end sequences of read length $250 \mathrm{bp}$ were carried out on the
Illumina HiSeq2500. The sequences are available in SRA (submission ID: SUB5871663).

\section{Bioinformatics analysis}

The raw reads were adapter-trimmed using TrimGalore version 0.6 .2 , followed by the removal of the low-quality bases (Phred value score $<$ Q30) by Sickle version 1.33. Duplicate reads were removed using FastUniq. The de novo assembly was performed using the Iterative Virus Assembler. The processed reads were aligned against individual pol gene sequences in very sensitive local mode using Bowtie 2 in order to select reads originated from pol genes and create a consensus gene. The subtyping was performed using REGA version 3. The selected reads were then aligned against pol protein sequences using the BLASTX program from the BLAST package. The best BLASTX hit was chosen for each read for the amino acid counting, which was performed by in-house script. The resistance was interpreted as per the mutation lists provided in the Stanford HIVDB, accessed on 6 January 2019 [39]. The complete script is available in github: https://github.com/neogilab/MiDRMPol_ SouthAfrica.

\section{Statistical analysis}

Descriptive statistic like mean, standard division (for normally distributed data), median, interquartile range (IQR), frequency in percentage were performed in GraphPad Prism version 8 (GraphPad Software, CA, US). The association between categorical variables were performed using Fisher's exact test. Comparison between

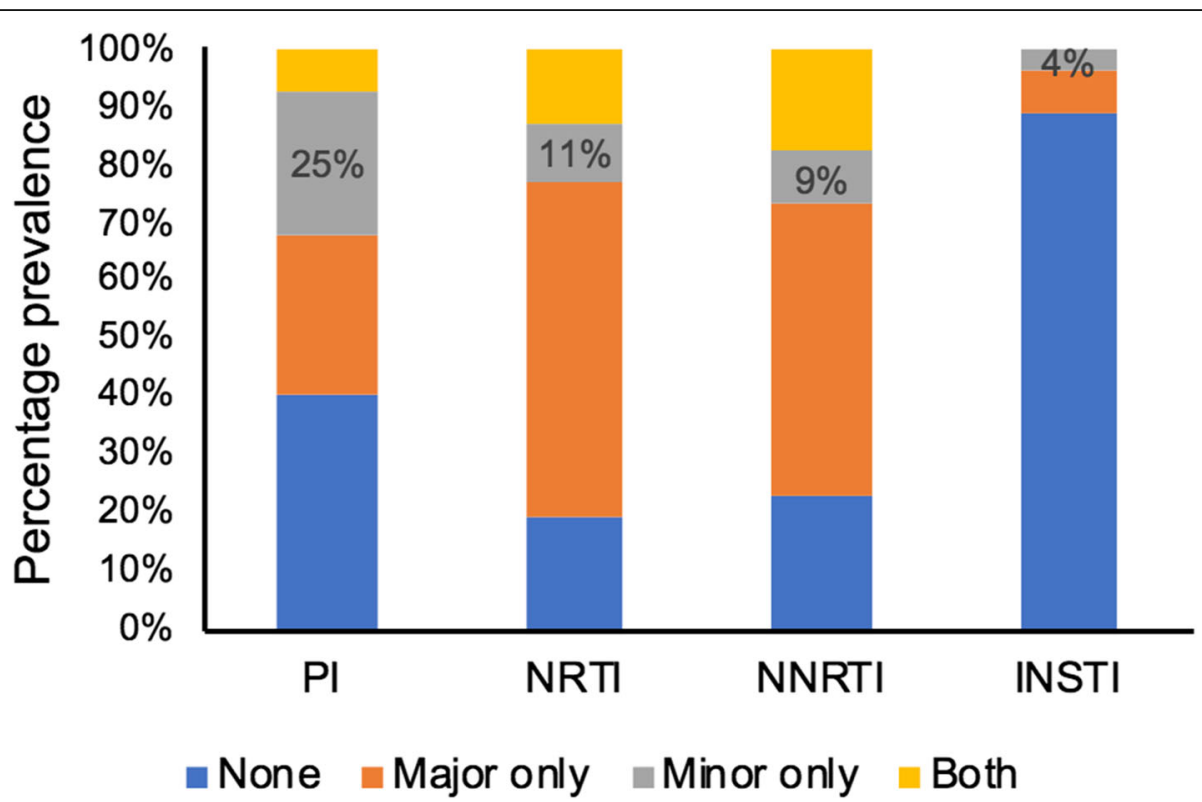

Fig. 1 Percentage prevalence of PI, NRTI, NNRTI and INI RAMs in minor ( $<20 \%$ of the population) and major ( $\geq 20 \%$ of the population) viral populations alone and together. The RAM in minor viral quasispecies are indicated 
two groups with continuous variable was performed with Students t-tests. The $p$-value less than 0.05 considered significant.

\section{Results}

Among the 67 samples sequenced, current treatment regimen data were not available for 11 samples, and therefore they were excluded from further analyses. Among the 56 patients, $5.3 \%(n=3)$ were on boosted ATV, while only one patient was on $\mathrm{DRV} / \mathrm{r}$ and the rest $(93 \% ; n=52)$ were receiving LPV/r. The median (range) viral load was 71,814 (937-5,500,000) copies/mL. HIV-1 subtyping identified 55 samples as HIV-1C and one as CRF02_AG. The NRTI, NNRTI and INI RAMs were observed among 25\% (14/56), $57 \%$ (32/56), 50\% (28/56) and 7\% (4/56), respectively.
Statistically significantly higher PI RAMs (25\%; 14/56) were observed only in the minor viral quasispecies compared to NNRTI (9\%; 5/56; $p=0.042)$ and INI RAM (4\%; $2 / 56 ; p=$ $0.002)$. A total of $41 \%(23 / 56)$ did not have any PI RAMs (Fig. 1). The complete mutation profile is presented in the supplementary Table 1 . There was no statistical difference in viral load $\left(\log _{10}\right.$ copies $\left./ \mathrm{mL}\right)$ in patients who only had PI DRM in minor population variants compared to patients who had only DRM in the major viral population [mean (SD): 4.92 (0.74) vs. $4.66(0.88) ; p=0.43]$.

All 56 patients harbored at least one DRM. Most of the DRMs in the minor viral quasispecies were observed in V82A mutation $(n=13)$ in protease and $\mathrm{K} 65 \mathrm{R}(n=5)$, $\mathrm{K} 103 \mathrm{~N}(n=7)$ and $\mathrm{M} 184 \mathrm{~V}(\mathrm{n}=5)$ in reverse transcriptase (Fig. 2). Despite no mention of use of any INIs by the

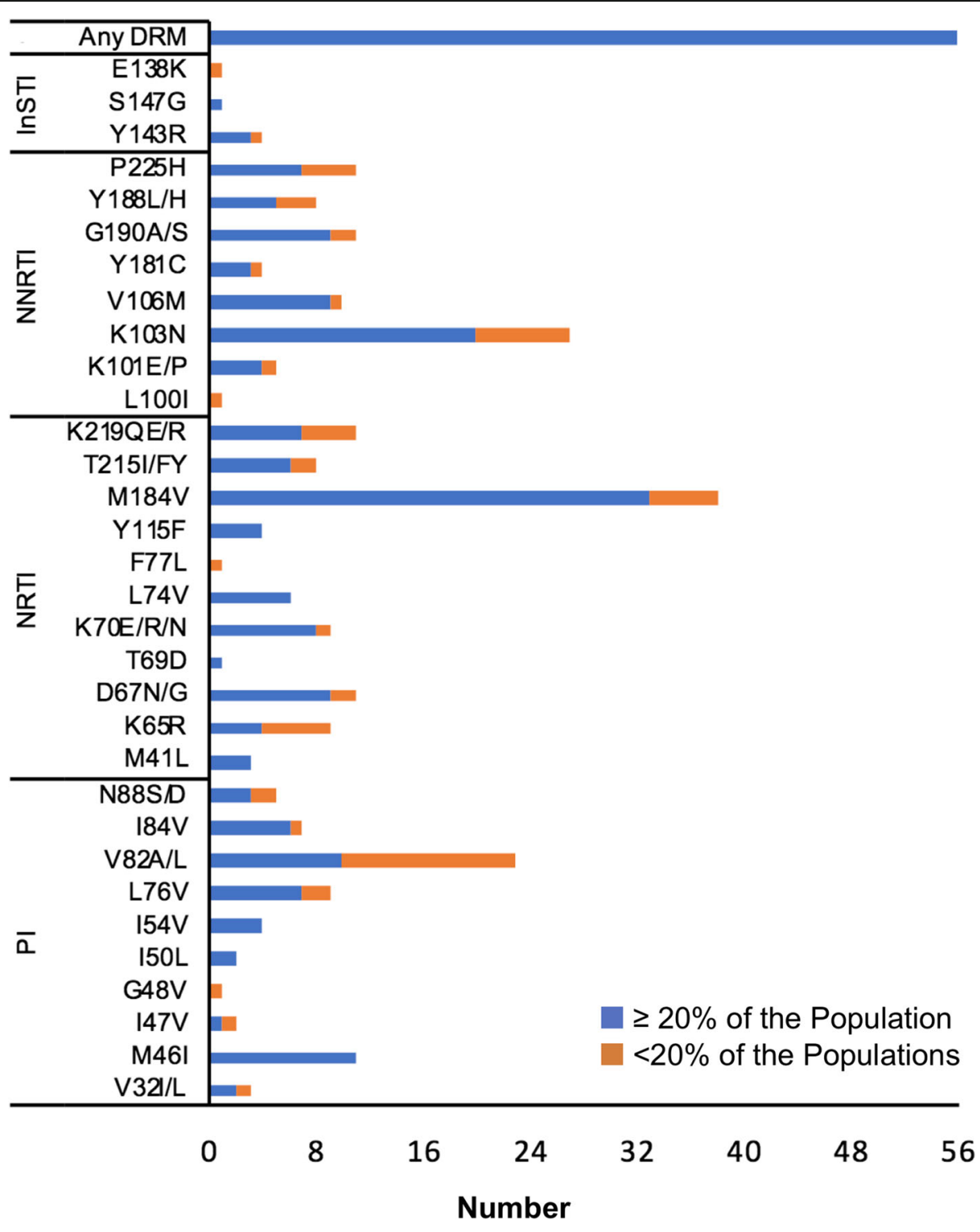

Fig. 2 Number of different RAMs in minor (<20\% of the population) and major ( $\geq 20 \%$ of the population) viral populations 
clinical reports, three patient sequences had the Y143R mutation in major viral quasispecies and one in minor viral quasispecies, which confers resistance to raltegravir (RAL). However, resistance to INI inhibitors was low in the settings. The predicted resistance pattern (as per the Stanford HIV Drug Resistance Database [HIVDB]) is given in Fig. 3. Half $(28 / 56)$ of the patients had doravirine cross resistance. There were two patients (ZA94 and ZA97) who were resistant to all classes of drugs, indicating the presence of extremely drug-resistant HIV-1 strains in South Africa.

\section{Discussion}

HTS assays have an intrinsic capability of detecting minority HIV-1 quasispecies mutation variants before they emerge as a majority variant under selection pressure, which might lead to virological failure. In this study we used HTS to type the DRM in both minor $(<20 \%$ of the population) and major ( $\geq 20 \%$ of the population) viral quasispecies and identified increased PI RAM in minor viral populations. Our study also indicated very low levels of transmitted INI RAMs in patients failing on a bPI-based regimen.

Earlier study have indicated that PI RAMs were uncommon in patients failing on second-line cART, with only $7 \%$ of patients on bPIs showing PI RAMs [40]. A study using Sanger sequencing indicated that $35 \%$ of the patients who had PI DRM failed on bPIs. A South African study conducted by Cohen et al. showed high-

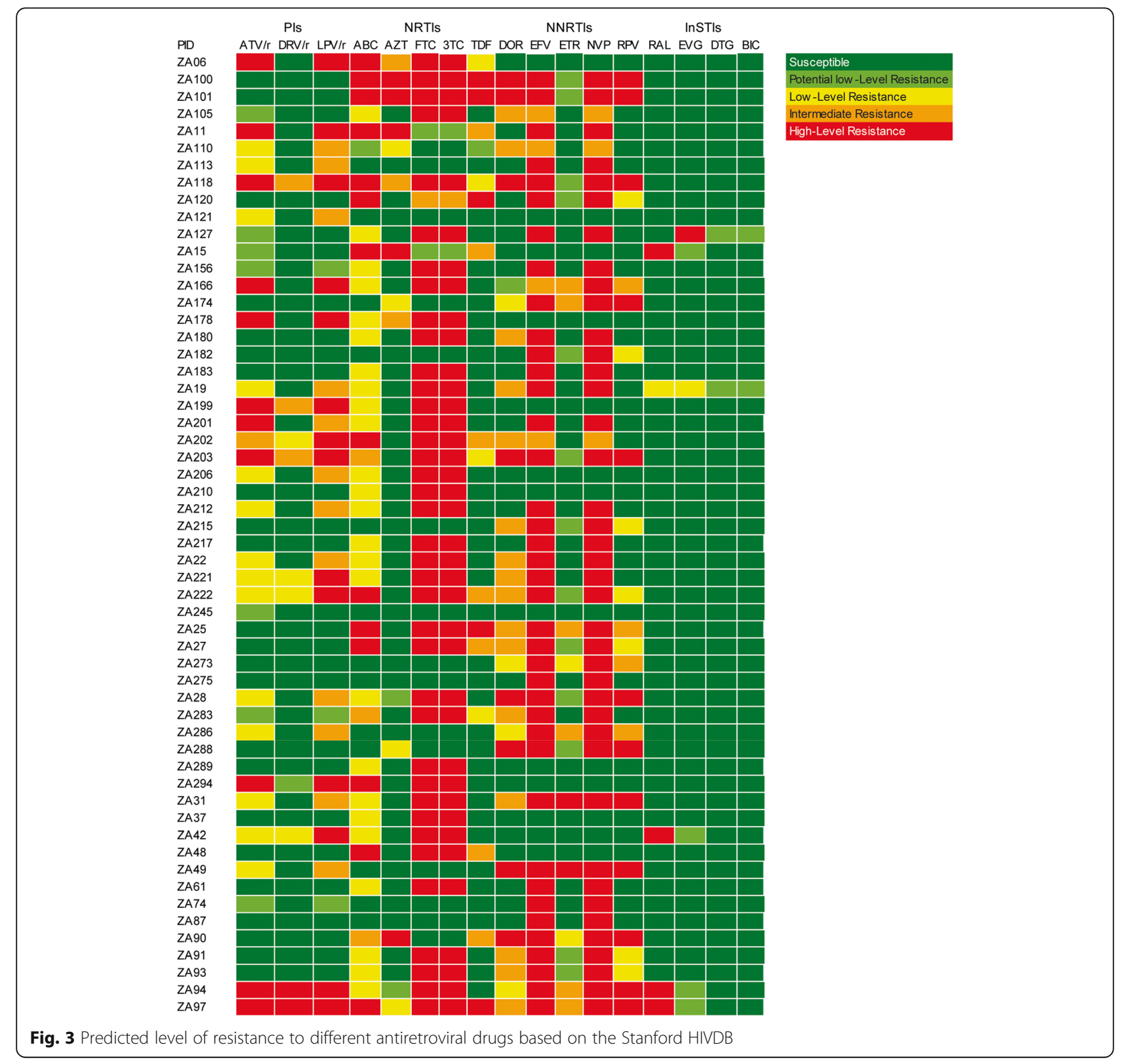


level resistance to $\mathrm{LPV} / \mathrm{r}$ in $76 / 339$ (22\%), while $45 / 339$ (13\%) had high-level resistance to atazanavir and 2/339 (0.6\%) had high-level resistance to darunavir [41]. Our study also showed that $34 \%$ of the patients had major PI RAMs in the major viral population, while $25 \%$ of the patients had PI DRM in the minor viral population. All the patients had at least one DRM. As most of the patients had high viral loads, there is a high chance of transmission of DRM if not treated timely. Furthermore, the PI RAMs in the minor viral population can evolve to become the majority under drug selection pressure.

Earlier studies indicated that HIV-1C has reduced susceptibility towards PIs without the emergence of major PI RAM [42] and that there is higher risk of virological failure [25]. Gag mutations can also confer reduced susceptibility towards PIs [43]. Furthermore, a study conducted in Nigeria reported PI RAMs in $62 \%$ of patients receiving PI-based second-line cART, with GRT being limited to patients with good adherence [44]. In East Africa, Inzaule et al. [45] found one or more major PI resistance mutations in $32 \%$ of unselected Kenyan patients with second-line ART failure and a median duration on PI-based ART of 3.1 years [45]. Few other observational studies in the African region have reported on ART exhaustion in 9 to $32 \%$ of patients failing second-line therapy $[46,47]$. Clinical studies also reported that secondline failure was frequent in South African settings [30], which could further increase the chance of transmission of primary DRMs.

Even though there is no indication of the patients being administered RAL, three of the patients in our study harbored Y143R mutation in $>20 \%$ of the population. Previous studies on HIV-1C have shown major INI mutations at baseline in less than $5 \%$ of patients from Ethiopia (T66I, E138K, Q148R, and Q148H) and South Africa (Q148H, T66S, E92G, S147G, T66A, Y143YF and $\mathrm{Y} 143 \mathrm{H})[3,20,28]$. However, the presence of INI RAMs in minor viral population is deemed not to have any clinical consequences [48].

\section{Conclusion}

We show that the use of high-throughput resistance testing for GRT can greatly improve the identification of acquired PI RAMs in bPI-failing patients. Using HTSGRT, PI RAMs (V82A) and RTI RAMs (K65R, M184V or $\mathrm{K} 103 \mathrm{~N}$ ) were identified in $<20 \%$ of the population that Sanger-based sequencing failed to identify, strengthening their role in detecting the acquired mutations early. In resource-limited settings, the use of these highthroughput resistance-testing assays might help in the early detection of minor variants before evolving as a majority variant. Acquired drug resistance poses a significant threat to achieving the WHO/UNAIDS 9090-90 targets for 2020. A recent WHO report also indicated an alarming surge in drug resistance across Africa [23]. Continuous surveillance, prevention, and monitoring at both minority variant and populationbased level are critical to achieving the $\mathrm{WHO} /$ UNAIDS 90-90-90 target.

\section{Potential conflicts of interest}

All authors declare no conflicts of interest.

\section{Supplementary Information}

The online version contains supplementary material available at https://doi. org/10.1186/s12879-021-05905-2.

Additional file $\mathbf{1}$ Table S1. Individual patient wise mutation profiling.

\section{Abbreviations}

ART: Antiretroviral therapy; ATV: Atazanavir; BIC: Bictegravir; bPI: boosted protease inhibitors; BLAST: Basic Local Alignment Search Tool;

CDNA: Complimentary Deoxyribonucleic acid; DNA: Deoxyribonucleic acid; DRM: Drug resistance mutations; DTG: Dolutegravir; EVG: Elvitegravir; GRT: Genotypic resistance testing; HIVDB: Human Immunodeficiency Virus Database; HTS: High-throughput sequencing; INI: Integrase inhibitors; INSTI: Integrase strand transfer inhibitor; NEB: New England Biolabs; NHLS: National Health Laboratory Services; NNRTI: Non-nucleoside reverse transcriptase inhibitors; NRTI: Nucleoside reverse transcriptase inhibitors; NVP: Nevirapine; PCR: Polymerase chain reaction; PI: Protease inhibitor; RAL: Raltegravir; RAM: Resistance-associated mutations; RNA: Ribonucleic acid; RT-PCR: Reverse Transcriptase Polymerase Chain Reaction;

PCR: Polymerase Chain Reaction; WHO: World Health Organization

\section{Acknowledgements}

We also acknowledge Ms. Mathilda Claassen and Dr. Shambhu Prasad Ganeshappa Aralaguppe for sample collection and technical support.

\section{Authors' contributions}

GBJ and UN conceptualized and designed the study. AEO performed laboratory experiments and detailed sequence analyses and wrote and edited the first draft of the manuscript. ATA and SG helped with detailed statistical analyses and constructed Figs. UN wrote the first draft of the manuscript and performed high-throughput sequencing experiments and sequence analyses. GBJ and UN helped with manuscript proofreading and editing. All authors read and approved the final manuscript. The authors would like to dedicate this manuscript to the loving memory of GBJ for his dedication to science and postgraduate education.

\section{Funding}

This study was funded by the following: National Research Foundation (NRF) of South Africa, the Poliomyelitis Research Foundation of South Africa and the NHLS Research Trust for studentship bursary We also thank Stellenbosch University and the Harry Crossley Foundation for additional financial support. UN is supported by a grant from the Swedish Research Council (201701330). GBJ is supported through the South African New Generation of Academics Programme (nGAP). The funders do not have any role in the study design, sample collection, data analysis and interpretation of the data.

\section{Availability of data and materials}

The raw FASTQ files dataset were deposited to NCBI-SRA. BioProject ID: PRJNA559799.

\section{Ethics approval and consent to participate}

The study was approved by the Health Research Ethics Committee of Stellenbosch University, South Africa (N15/08/071). The study was conducted according to the ethical guidelines and principles of the Declaration of Helsinki 2013, the South African Guidelines for Good Clinical Practice and the Medical Research Council Ethical Guidelines for Research. A waiver of written informed consent was awarded to conduct sequence analyses on these 
samples by the Health Research Ethics Committee of Stellenbosch University, South Africa.

\section{Consent for publication}

Not applicable.

\section{Competing interests}

The authors declare that they have no competing interests.

Received: 27 May 2020 Accepted: 16 February 2021

Published online: 25 February 2021

\section{References}

1. Ji H, Enns E, Brumme CJ, Parkin N, Howison M, Lee ER, et al. Bioinformatic data processing pipelines in support of next-generation sequencing-based HIV drug resistance testing: the Winnipeg consensus. J Int AIDS Soc. 2018; 21:1-14.

2. Derache A, Iwuji CC, Baisley K, Danaviah S, Marcelin AG, Calvez V, et al. Impact of next-generation sequencing defined human immunodeficiency virus pretreatment drug resistance on virological outcomes in the ANRS 12249 treatment-as-prevention trial. Clin Infect Dis. 2019;69:207-14.

3. Telele NF, Kalu AW, Gebre-Selassie S, Fekade D, Abdurahman S, Marrone G, et al. Pretreatment drug resistance in a large countrywide Ethiopian HIV-1C cohort: a comparison of sanger and high-throughput sequencing /631/326/ $2521 / 631 / 337 / 151 / 1431 / 38 / 23 / 38 / 77 / 38 / 90 / 14 / 63 / 38 / 43 / 38 / 47 / 42 / 40$ article. Sci Rep. 2018:8:1-10.

4. Simen BB, Simons JF, Hullsiek KH, Novak RM, MacArthur RD, Baxter JD, et al. Low-abundance drug-resistant viral variants in chronically HIV-infected, antiretroviral treatment-naive patients significantly impact treatment outcomes. J Infect Dis. 2009;199:693-701. https://doi.org/10.1086/596736.

5. Archer J, Rambaut A, Taillon BE, Harrigan PR, Lewis M, Robertson DL. The evolutionary analysis of emerging low frequency HIV-1 CXCR4 using variants through time-an ultra-deep approach. PLoS Comput Biol. 2010;6:e1001022. https://doi.org/10.1371/journal.pcbi.1001022.

6. Church JD, Jones D, Flys T, Hoover D, Marlowe N, Chen S, et al. Sensitivity of the ViroSeq HIV-1 genotyping system for detection of the K103N resistance mutation in HIV-1 subtypes a, C, and D. J Mol Diagnostics. 2006;8: 430-2. https://doi.org/10.2353/jmoldx.2006.050148.

7. Goodman DD, Zhou Y, Margot NA, McColl DJ, Zhong L, Borroto-Esoda K, et al. Low level of the K103N HIV-1 above a threshold is associated with virological failure in treatment-naive individuals undergoing efavirenzcontaining therapy. AIDS. 2011;25:325-33. https://doi.org/10.1097/QAD. Ob013e3283427dcb.

8. Balduin M, Oette M, Däumer MP, Hoffmann D, Pfister HJ, Kaiser R. Prevalence of minor variants of HIV strains at reverse transcriptase position 103 in therapy-naïve patients and their impact on the virological failure. J Clin Virol. 2009;45:34-8. https://doi.org/10.1016/j.jcv.2009.03.002.

9. Tsibris AMN, Korber B, Arnaout R, Russ C, Lo C-C, Leitner T, et al. Quantitative deep sequencing reveals dynamic HIV-1 escape and large population shifts during CCR5 antagonist therapy in vivo. PLoS One. 2009;4: e5683. https://doi.org/10.1371/journal.pone.0005683.

10. Archer J, Braverman MS, Taillon BE, Desany B, James I, Harrigan PR, et al. Detection of low-frequency pretherapy chemokine (CXC motif) receptor 4 (CXCR4)-using HIV-1 with ultra-deep pyrosequencing. AIDS. 2009;23:1209_ 18. https://doi.org/10.1097/QAD.0b013e32832b4399.

11. Cozzi-Lepri A, Noguera-Julian M, Di Giallonardo F, Schuurman R, Däumer M, Aitken S, et al. Low-frequency drug-resistant HIV-1 and risk of virological failure to first-line NNRTI-based ART: a multicohort European case-control study using centralized ultrasensitive 454 pyrosequencing. J Antimicrob Chemother. 2015;70:930-40. https://doi.org/10.1093/jac/dku426.

12. Jackson JB, Becker-Pergola G, Guay LA, Musoke P, Mracna M, Fowler MG, et al. Identification of the $\mathrm{K} 103 \mathrm{~N}$ resistance mutation in Ugandan women receiving nevirapine to prevent HIV-1 vertical transmission. AIDS. 2000;14: F111-5. https://doi.org/10.1097/00002030-200007280-00001.

13. Johnson JA, Li J, Morris L, Martinson N, Gray G, Mclntyre J, et al. Emergence of drug-resistant HIV-1 after Intrapartum Administration of Single-Dose Nevirapine is Substantially Underestimated. J Infect Dis. 2005;192:16-23. https://doi.org/10.1086/430741.

14. Hauser A, Mugenyi K, Kabasinguzi R, Bluethgen K, Kuecherer C, Harms G, et al. Detection and quantification of minor human immunodeficiency virus type 1 variants harboring $\mathrm{K} 103 \mathrm{~N}$ and $\mathrm{Y} 181 \mathrm{C}$ resistance mutations in subtype a and D isolates by allele-specific real-time PCR. Antimicrob Agents Chemother. 2009;53:2965-73. https://doi.org/10.1128/AAC.01672-08.

15. Peuchant $O$, Thiébaut $R$, Capdepont S, Lavignolle-Aurillac V, Neau D, Morlat $P$, et al. Transmission of HIV-1 minority-resistant variants and response to first-line antiretroviral therapy. AIDS. 2008;22:1417-23. https://doi.org/10.1 097/QAD.0b013e3283034953.

16. Metzner KJ, Giulieri SG, Knoepfel SA, Rauch P, Burgisser P, Yerly S, et al. Minority quasispecies of drug-resistant HIV-1 that lead to early therapy failure in treatment-naive and -adherent patients. Clin Infect Dis. 2009;48: 239-47. https://doi.org/10.1086/595703.

17. Li JZ. Low-frequency HIV-1 drug resistance mutations and risk of NNRTIbased antiretroviral treatment failure. JAMA. 2011;305:1327. https://doi.org/1 0.1001/jama.2011.375.

18. Sidhu G, Schuster L, Liu L, Tamashiro R, Li E, Langaee T, et al. A single variant sequencing method for sensitive and quantitative detection of HIV-1 minority variants. Sci Rep. 2020;10:8185. https://doi.org/10.1038/s41598-02065085-y.

19. Paredes R, Lalama CM, Ribaudo HJ, Schackman BR, Shikuma C, Giguel F, et al. Pre-existing minority drug-resistant HIV-1 variants, adherence, and risk of antiretroviral treatment failure. J Infect Dis. 2010;201:10012609593609500.

20. Obasa AE, Mikasi SG, Brado D, Cloete R, Singh K, Neogi U, et al. Drug Resistance Mutations Against Protease, Reverse Transcriptase and Integrase Inhibitors in People Living With HIV-1 Receiving Boosted Protease Inhibitors in South Africa. Front Microbiol. 2020;11 March:438. doi:https://doi.org/10.33 89/fmicb.2020.00438.

21. Metzner KJ, Scherrer AU, Von Wyl V, Böni J, Yerly S, Klimkait T, et al. Limited clinical benefit of minority K103N and Y181C-variant detection in addition to routine genotypic resistance testing in antiretroviral therapy-naive patients. Aids. 2014;28:2231-9.

22. Inzaule SC, Hamers RL, Noguera-Julian M, Casadellà M, Parera M, de Wit TFR, et al. Primary resistance to integrase strand transfer inhibitors in patients infected with diverse HIV-1 subtypes in sub-Saharan Africa. J Antimicrob Chemother. 2018;73:1167-72.

23. World Health Organization (WHO). HIV Drug Resistance Report. 2019. http:// scholar.google.com/scholar/Who hiv drug resistance report 2012.

24. Meintjes G, Moorhouse MA, Carmona S, Davies N, Dlamini S, Van Vuuren C, et al. Adult antiretroviral therapy guidelines 2017. South Afr J HIV Med. 2017;18:24 pages. doi:https://doi.org/10.4102/sajhivmed.v18i1.776.

25. Häggblom A, Svedhem V, Singh K, Sönnerborg A, Neogi U. Virological failure in patients with HIV-1 subtype C receiving antiretroviral therapy: an analysis of a prospective national cohort in Sweden. Lancet HIV. 2016;3: e166-74.

26. Sutherland KA, Collier DA, Claiborne DT, Prince $J$, Deymier MJ, Goldstein RA, et al. Wide variation in susceptibility of transmitted/founder HIV-1 subtype $\mathrm{C}$ isolates to protease inhibitors and association with in vitro replication efficiency. Sci Rep. 2016;6.

27. Ajose O, Mookerjee S, Mills EJ, Boulle A, Ford N. Treatment outcomes of patients on second-line antiretroviral therapy in resource-limited settings: a systematic review and meta-analysis. Aids. 2012;26:929-38.

28. Brado D, Obasa AE, Ikomey GM, Cloete R, Singh K, Engelbrecht $S$, et al. Analyses of HIV-1 integrase sequences prior to south African national HIVtreatment program and availability of integrase inhibitors in Cape Town. South Africa Sci Rep. 2018;8:4709. https://doi.org/10.1038/s41598-018-22914-5.

29. Moorhouse M, Maartens G, Venter WDF, Moosa MY, Steegen K, Jamaloodien $\mathrm{K}$, et al. Third-line antiretroviral therapy program in the south African public sector: cohort description and Virological outcomes. J Acquir Immune Defic Syndr. 2019;80:73-8.

30. Collier D, Iwuji C, Derache A, De Oliveira T, Okesola N, Calmy A, et al. Virological outcomes of second-line protease inhibitor-based treatment for human immunodeficiency virus type 1 in a high-prevalence rural south African setting: a competing-risks prospective cohort analysis. Clin Infect Dis. 2017:64:1006-16.

31. Fisher R, Van Zyl GU, Travers SAA, Pond LK, Engelbrech S, Murrell B. Deep sequencing reveals minor protease resistance mutations in patients failing a protease inhibitor regimen. J Virol. 2012;86:6231-7.

32. Larder BA, Kohli A, Kellam P, Kemp SD, Kronick M, Henfrey RD. Quantitative detection of HIV-1 drug resistance mutations by automated DNA sequencing. Nature. 1993;365:671-3. https://doi.org/10.1038/365671a0

33. Palmer S, Kearney M, Maldarelli F, Halvas EK, Bixby CJ, Bazmi H, et al. Multiple, linked human immunodeficiency virus type 1 drug resistance 
mutations in treatment-experienced patients are missed by standard genotype analysis. J Clin Microbiol. 2005;43:406-13. https://doi.org/10.1128/ JCM.43.1.406-413.2005.

34. Obasa AE, Engelbrecht $S$, Jacobs GB. Near full-length HIV-1 subtype B sequences from the early south African epidemic, detecting a BD unique recombinant form (URF) from a sample in 1985. Sci Rep. 2019;9:1-7.

35. Halvas EK, Wiegand A, Boltz VF, Kearney M, Nissley D, Wantman M, et al. Low Frequency Nonnucleoside Reverse-Transcriptase Inhibitor-Resistant Variants Contribute to Failure of Efavirenz-Containing Regimens in Treatment-Experienced Patients. J Infect Dis. 2010;:100126095936095-000. doi:https://doi.org/10.1086/650542.

36. Simen BB, Braverman MS, Abbate I, Aerssens J, Bidet Y, Bouchez O, et al. An international multicenter study on HIV-1 drug resistance testing by 454 ultra-deep pyrosequencing. J Virol Methods. 2014;204:31-7. https://doi.org/1 0.1016/j.jviromet.2014.04.007.

37. Mohamed S, Penaranda G, Gonzalez D, Camus C, Khiri H, Boulmé R, et al. Comparison of ultra-deep versus sanger sequencing detection of minority mutations on the HIV-1 drug resistance interpretations after virological failure. AIDS. 2014;28:1315-24. https://doi.org/10.1097/QAD.00000000000002 67.

38. Obasa AE, Ashokkumar M, Neogi U, Jacobs GB. Mutations in long terminal repeats $\mathrm{KB}$ transcription factor binding sites in plasma virus among south African people living with HIV-1. AIDS Res Hum Retrovir. 2019;35:572-6.

39. Rhee S, Fessel WJ, Liu TF, Marlowe NM, Rowland CM, Rode RA, et al. Predictive value of HIV-1 genotypic resistance test interpretation algorithms. J Infect Dis. 2009;200:453-63.

40. Wallis CL, Mellors JW, Venter WDF, Sanne I, Stevens W. Protease inhibitor resistance is uncommon in HIV-1 subtype $C$ infected patients on failing second-line Lopinavir/r-containing antiretroviral therapy in South Africa. AIDS Res Treat. 2011;2011:769627.

41. Pillay M, Khan A, Govender K, Chimukangara R, Ellapen M MP. HIV drug resistance in adults failing protease inhibitor (PI)-based antiretroviral therapy (ART) in KwaZulu-Natal. 27th Int Work HIV Drug Resist Treat Strateg. 2018.

42. Sutherland KA, Parry CM, McCormick A, Kapaata A, Lyagoba F, Kaleebu P, et al. Evidence for reduced drug susceptibility without emergence of major protease mutations following protease inhibitor monotherapy failure in the SARA trial. PLoS One. 2015;10:1-14

43. Robert van Domselaar, Duncan T Njenda, Rohit Rao, Anders Sönnerborg, Kamalendra Singh UN. HIV-1 Subtype C with PYxE Insertion Has Enhanced Binding of Gag-p6 to Host Cell Protein ALIX and Increased Replication Fitness. J Virol. 2019;93:1-14.

44. Rawizza HE, Chaplin B, Meloni ST, Darin KM, Olaitan O, Scarsi KK, et al. Accumulation of protease mutations among patients failing second-line antiretroviral therapy and response to salvage therapy in Nigeria. PLoS One. 2013;8:1-8.

45. Inzaule SC, Hamers RL, Mukui I, Were K, Owiti P, Kwaro D, et al. Emergence of untreatable, multidrug-resistant HIV-1 in patients failing second-line therapy in Kenya. Aids. 2017;31:1495-8.

46. Maiga Al, Fofana DB, Cisse M, Diallo F, Maiga MY, Traore HA, et al. Characterization of HIV-1 antiretroviral drug resistance after second-line treatment failure in Mali, a limited-resources setting. J Antimicrob Chemother. 2012;67:2943-8.

47. Steegen K, Carmona S, Bronze M, Papathanasopoulos MA, van Zyl G, Goedhals D, et al. Moderate levels of pre-treatment HIV-1 antiretroviral drug resistance detected in the first south African National Survey. PLoS One. 2016;11:e0166305.

48. Nguyen T, Fofana DB, Lê MP, Charpentier C, Peytavin G, Wirden M, et al. Prevalence and clinical impact of minority resistant variants in patients failing an integrase inhibitor-based regimen by ultra-deep sequencing. J Antimicrob Chemother. 2018;73:2485-92.

\section{Publisher's Note}

Springer Nature remains neutral with regard to jurisdictional claims in published maps and institutional affiliations.

Ready to submit your research? Choose BMC and benefit from:

- fast, convenient online submission

- thorough peer review by experienced researchers in your field

- rapid publication on acceptance

- support for research data, including large and complex data types

- gold Open Access which fosters wider collaboration and increased citations

- maximum visibility for your research: over $100 \mathrm{M}$ website views per year

At BMC, research is always in progress.

Learn more biomedcentral.com/submissions 